\title{
A MORALIDADE JURÍDICA DOS DIREITOS HUMANOS COMO CONDIÇÃO DE SUA UNIVERSALIDADE
}

\author{
Doglas Cesar Lucas ${ }^{1}$
}

\section{RESUMO}

O presente texto pretende sustentar a presença de uma moralidade jurídica nos direitos humanos como condição de sua universalidade. Iniciando o percurso pelo conceito de direitos morais e após visitar a aproximação do direito e da moral presentes na leitura kantiana, chega-se à análise da moralidade jurídica dos direitos humanos, que é entendida como dever, tanto moral como jurídico, de reconhecimento que as pessoas se devem umas as outras, um dever que todos os indivíduos assumem, indistintamente, de respeitarem um conjunto de obrigações recíprocas que geram uma vantagem para todos, uma vez que se fundamentam na humanidade do homem como tal.

Palavras-Chave: Direitos humanos. Kant. Moral jurídica. Otfried Höffe.

\section{INTRODUÇÃO}

Apesar de nunca ter saído de cena, o problema teórico e prático dos direitos humanos adquire uma peculiar importância no contexto da sociedade global. Novas formas de produção da sociabilidade dão visibilidade aos problemas que já existiam, mas que estavam encobertos ou atenuados pelas cortinas conceituais modernas e pela limitação real dos Estados-nação em responder aos desafios de um cenário político, econômico e cultural cada vez mais complexo. Os homens e suas respostas permanecem vinculados aos Estados nacionais, enquanto os problemas que pontuam os Direitos Humanos ganham escala mundial. Isso equivale dizer que as ações e os riscos globais são acompanhados, precariamente, apenas por respostas nacionais e particularistas, por respostas cada vez mais insuficientes, apesar, é preciso reconhecer, de crescerem as tentativas teóricas e políticas de se delinear respostas cosmopolitas.

Num cenário de aproximações e afastamentos, de desafios globais que afetam o homem indistintamente de suas relações particulares com a nação, a religião e o local, respostas jurídico-políticas fundamentadas numa humanidade de convergência, que reconhecem as diferenças sem negar o "humano", que promovem o diálogo em vez de novos fundamentalismos, são especialmente importantes para a definição de uma cultura de direitos humanos efetivamente voltada para além das comunidades, para além dos Estados, para além da cidadania nacional, e especialmente centrada na construção um paradigma globalizador de emancipação do homem.

Nessa direção, o presente texto tem a intenção de defender uma moralidade jurídica que se constitui como uma condição de possibilidade para o fundamento da 
universalidade dos direitos humanos. Para atingir esse propósito, o trabalho foi dividido em três partes. Logo no primeiro item são retomadas questões recorrentes na teoria jurídica sobre a tese dos direitos morais, o que se faz especialmente por meio das elaborações teóricas de Francisco Laporta. O segundo momento é dedicado para tratar da moralidade do direito em Kant. $O$ terceiro e último momento serão dedicados à idéia, defendida por Höffe, de que os direitos humanos, junto com a democracia, compõem o conteúdo daquilo que ele denomina de moral jurídica, capaz de obrigar mutuamente os indivíduos e as instituições a respeitarem essa mesma moralidade. Enfim, sustenta-se que os direitos humanos são patrimônio comum da humanidade e que a sua universalidade mediadora (mas não planificadora) é indispensável para a promoção de um diálogo intercultural e para a elaboração de propostas cosmopolitas de emancipação social.

\section{OS DIREITOS HUMANOS COMO DIREITOS MORAIS}

Contrária ao relativismo das doutrinas historicistas, a tese dos direitos humanos como direitos morais surge com a pretensão de defender um fundamento ético para se pensar a universalidade dos direitos humanos, sem, contudo, ter que apelar para o jusnaturalismo e sem ter que se reduzir ao positivismo. De uma forma geral, a teoria dos direitos humanos como direitos morais sustenta que existem exigências éticas e princípios morais que dizem respeito ao homem como tal e que funcionam como boas razões ou justificativas racionais para a ação jurídica, de modo que seu conteúdo moral deve ser reconhecido pelo direito positivo e, com isso, ser capaz de gerar obrigações e responsabilidades mútuas.

De acordo com Francisco Laporta, ${ }^{2}$ defensor dessa corrente, a malograda idéia de que os direitos são componentes privativos dos sistemas jurídicos advém da confusão que se faz entre os direitos propriamente ditos e as técnicasinstrumentos de proteção desses mesmos direitos. ${ }^{3}$ Alerta Laporta que os direitos são algo que estão antes das ações, das pretensões ou exigências, antes dos procedimentos normativos que visam protegê-los. Sugere, nesse sentido, que quando usamos a 'noção de 'direito' não estamos fazendo referência a certas normas primárias ou secundárias de certo sistema normativo, mas nos referindo à razão que se apresenta como justificação da existência de tais normas". 4 Um direito, nesse viés, é um bem tal que se constitui como uma forte razão para que seja articulado, em favor de todas as pessoas, um status normativo por meio da imposição de deveres e obrigações que podem ser reclamados de modo processual perante o Estado. Por isso, não se pode confundir aquilo que fundamenta o direito, que possibilita sua condição de universalidade, com a sua própria positividade ou mesmo com as condições históricas que construíram o arsenal instrumental de proteção desses direitos. $^{5}$

Se a universalidade dos direitos humanos reside, então, na titularidade que todos os seres humanos possuem para exigirem tais direitos, torna-se precária a sua identificação exclusiva com a noção de direitos legais - os quais são devidos somente àqueles que participam de uma dada comunidade que reconhece positivamente referidos direitos - e, ainda, indispensável sua justificação de natureza ética, capaz de reconhecê-los como direitos morais, como direitos que, a um só tempo, obrigam e legitimam a adoção de instrumentos jurídicos e ações políticas 
concretas dirigidas à proteção desses mesmos direitos, independentemente de qualquer condição outra que não a universalidade do homem como tal. Como direitos morais universais, os direitos humanos são devidos a cada um dos membros da classe ser humano, na satisfação de uma posição, situação, aspecto, estado de coisas, etc., que se considere moralmente um bem que se constitui como uma razão forte para se articular uma proteção normativa em seu favor. ${ }^{6}$

Compreendidos dessa maneira, os direitos humanos visam fundamentar a exigência de obrigações gerais, obrigações dirigidas a todos, e não a especificidade de obrigações posicionadas de forma circunstancial e decorrente de uma dada situação institucional ou cultural. Por conseguinte, Estados e indivíduos são compelidos, individual ou coletivamente, a colaborarem ativamente na proteção e na garantia efetiva dos bens que compõem o núcleo dos direitos básicos, bem como de se absterem de interferir lesivamente em sua promoção. A força dos direitos humanos, então, não decorre de seu reconhecimento positivo, senão que os direitos humanos são fortes porque carregam eles mesmos uma potência capaz de exigir obrigações e medidas de proteção.

Diante da ocorrência de um conflito entre diferentes posições morais, sejam individuais ou coletivas, Laporta destaca que os direitos humanos são concebidos como postulados morais mais fortes que aqueles que não geram direitos, de modo que os direitos humanos só podem ser confrontados por outras exigências morais do mesmo nível, ou seja, por outros direitos humanos. Um exemplo atual desse enfrentamento pode ser verificado entre os utilitaristas e os defensores dos direitos morais. Ao tratar dessa disputa moral entre um direito básico individual e uma medida de interesse geral, Ronald Dworkin ${ }^{7}$ refere que, quando uma pessoa tem direito a algo, o Estado não pode negar este direito nem que seja em nome de um interesse ou de uma utilidade geral. Os direitos individuais, nessa concepção, funcionam como trunfos morais contra o Estado, que não poderá utilizar argumentos de política para efetivar ações públicas que neguem os direitos individuais decorrentes de um princípio.

Nessa mesma direção, Carlos Nino refere que as normas jurídicas, se levadas ao extremo de sua justificação, não conseguem encontrar um juízo também jurídico que legitime a aceitação de seu conteúdo, especialmente porque não é factível se percorrer infinitamente para além da autoridade que elaborou determinada norma. Posto que os princípios que conferem legitimidade a essa autoridade não são de cunho jurídico e sim moral, as decisões dessa autoridade se fundamentam, em última instância, em normas morais, mesmo quando as decisões invocam prescrições de um texto constitucional que estabelece direitos no sentido jurídico do termo. Da mesma forma, um juízo normativo que é aceito em razão de suas próprias virtudes (tal como se caracterizam os direitos humanos), e não por ter sido elaborado por uma autoridade competente, pode ser considerado como derivativo de um juízo moral. Assim, os direitos humanos, na acepção de Nino, são direitos morais que a ordem jurídica reconhece, mas cuja existência independe desse reconhecimento. $O$ autor argentino não está se referindo a uma moral positiva e sim a uma moral ideal ou crítica, compreendida como "um sistema de princípios e juízos de valor que possuem validade objetiva, ou seja, valem em todo tempo e lugar, independentemente de seu reconhecimento fático, e que são acessíveis pela razão humana".8 
Nino distingue dois tipos de direitos morais: os direitos fundamentais e os direitos institucionais. Os primeiros são aqueles direitos constituídos por normas morais stricto sensu e que não dependem do seu reconhecimento legal; os direitos morais institucionais, por sua vez, são aqueles direitos elaborados por autoridade legitimada moralmente. Com isso, o autor não defende que os direitos (jurídicos) dependam necessariamente dos direitos fundamentais, mas que sejam dependentes dos direitos morais institucionais. Tratando propriamente dos direitos humanos, Nino refere que os mesmos decorrem de três princípios morais categóricos, reconhecidos e devidos para todos os seres humanos, quais sejam: inviolabilidade, autonomia e dignidade da pessoa humana. ${ }^{9}$

Os direitos morais, ainda de acordo com Laporta, não são renunciáveis nem mesmo pela própria vontade de seus titulares. A idéia fundamental dessa irrenunciabilidade assenta-se na premissa de que não se pode equiparar, em sua dimensão moral, a aceitação de um direito ao consentimento que nega a abrangência desse mesmo direito, ou seja, não se pode afastar o direito em razão de que o mesmo não seja conhecido pelos seus titulares, eis que, por medo ou ignorância um homem pode aceitar uma violação ou uma desvantagem, sem que isso signifique que o teor dessa violação tenha sido compreendido ou aceito do ponto de vista moral. É essa idéia de irrrenunciabilidade que constitui o cerne da reciprocidade, pois, como diria Otfried Höffe, somente por intermédio da reciprocidade é que se pode garantir a realização de um interesse irrenunciável.

\section{A MORALIDADE DO DIREITO EM KANT}

Os ensinamentos de Kant são evidentes em todas as proposições que tratam de defender um dever de reciprocidade moral e positiva que emana dos direitos humanos. Basta lembrar que o filósofo de Königsberg estabeleceu as bases modernas da filosofia transcendental que permitiu entender racionalmente e a priori os juízos morais, possibilitando a fundamentação do conceito de direito baseado na lei moral. $O$ homem é, segundo Kant, um ser racional que deve utilizar sua razão para tratar das questões de natureza moral, pois as boas razões para a ação humana não podem estar condicionadas a instintos, inclinações ou preferências, mas precisam estar de acordo com a moralidade do homem como tal, com sua dignidade, que se revela em tratar os homens como um fim em si mesmo e não como meio. O agir moral, dessa forma, é uma decorrência inevitável da compreensão racional que o homem tem de si mesmo como ser dotado de dignidade e como ser que somente poderá exercer sua autonomia numa máxima condição de liberdade, que pode ser alcançada por todos os homens em razão de sua humanidade.

A condição de moralidade (humanidade enquanto capaz de moralidade), nesse sentido, é a única condição que pode fazer de um ser racional um fim em si mesmo, o que torna a ação moral uma ação por dever, uma ação segundo uma máxima racional universal ou, em outras palavras, de acordo com um imperativo categórico que pode ser assim descrito: "age só segundo máxima tal que possas ao mesmo tempo querer que ela se torne lei universal", ou, numa segunda fórmula, "age como se a máxima de tua ação devesse se tornar, pela tua vontade, lei 
universal da natureza", ${ }^{10}$ ou, ainda em uma terceira formulação, "age de tal maneira que possas usar a humanidade, tanto em tua pessoa como na pessoa de qualquer outro, sempre e simultaneamente como fim e nunca simplesmente como meio". 11 Kant refere que os imperativos podem ser de dois tipos. Os imperativos categóricos, que se apresentam como verdadeiros mandamentos morais que indicam para uma ação boa em si mesma e independentemente de qualquer finalidade; são, portanto, incondicionais. Já os imperativos hipotéticos são de natureza condicionada e ordenam um comportamento como necessário para a obtenção de um determinado resultado desejado; condicionam, então, os deveres, de modo objetivo, para a satisfação de um propósito. $O$ imperativo categórico e a liberdade são, segundo Kant, ${ }^{12}$ os dois princípios dos quais se deriva toda a ação humana considerada sob o ponto de vista moral.

O pensamento kantiano inaugurou um jusnaturalismo racionalista que, diferentemente das propostas jusnaturalistas anteriores, permitiu libertar a discussão dos direitos do homem enquanto direitos morais stricto sensu das condições empíricas que alcançam sua existência histórica e factual. Kant emancipou as obrigações morais, e em certa medida as obrigações jurídicas baseadas na moral, da conjuntura dos eventos históricos, uma vez que não se pode, segundo ele, encontrar um momento inicial na história que indique o ponto de partida que levou os homens a adotarem uma mentalidade jurídica. Isso, por outro lado, não significa que se possa desprestigiar, segundo o autor, a positividade dos direitos humanos. Não é disso que está se falando, mas da existência de uma necessária correspondência de obrigações morais recíprocas, que devem ser reconhecidas pelo homem como condição mesma de sua humanidade. Não constituem obrigações decorrentes de inclinações e interesses particulares, mas sim uma necessária imposição racional que obriga os homens reciprocamente, permitindo desse modo a coexistência humana num máximo de igual liberdade possível a todos os homens. Nisso reside a proibição de se tratar o homem como meio e o correspondente reconhecimento de sua dignidade como atributo moral de sua humanidade.

Há uma certa correspondência entre moral e direito em Kant que, segundo Höffe, não é compreendida por todos os seus intérpretes. ${ }^{13}$ Para Höffe, existem dois conceitos de imperativo categórico: um mais amplo, que corresponde a obrigação incondicional de uma práxis; e um conceito mais reduzido e especificamente ético, que diz respeito às obrigações incondicionais relativas aos princípios autônomos da vontade humana. No primeiro caso, é válido para o direito; no segundo, para a ética, para a moralidade. Isso quer dizer que, se tomada de forma ampla, a moral também se refere ao direito, não na qualidade de máximas, mas relacionada às ações humanas externas que são acompanhadas de coerção. Dito de outra maneira, a moral, em sentido estrito, refere-se às obrigações e às ações de sentido pessoal interno, independentemente da existência de coações externas; a moral, em sentido amplo, por sua vez, diz respeito a todo âmbito da razão pura prática, suas leis e obrigações, abarcando, assim, tanto a moralidade quanto o direito. ${ }^{14}$

A legislação jurídica somente exige uma conformidade exterior; a lei ética exige apenas uma adequação com o dever interno, pessoal. Mas as formas de obrigar, da lei moral e da lei jurídica, não são contraditórias, mas complementares. Isso porque tanto o direito quanto a moral estabelecem deveres, os quais, porém, 
no caso da moral, não podem ser simplesmente exteriores, uma vez que têm, como fim um dever em si mesmo e exigem que a ação se dê em respeito à lei moral, decorrente de um sentimento a priori que não é passível de ser exteriorizado. ${ }^{15}$ Já os deveres que o direito impõe podem ser verificados em sua exterioridade, pois dizem respeito à conformidade com uma lei externa. Para Kant, então, o direito tem a função de tornar possível a coexistência da liberdade exterior, regulando o livre arbítrio, para se garantir o máximo de liberdade igual para todas as pessoas; ou seja, preservando-se o livre arbítrio de todos, a liberdade subsiste. 0 direito é diretamente vinculado e inseparável de sua capacidade de obrigar aqueles que se opõem ao seu livre exercício, notadamente porque há uma obrigação geral recíproca com a liberdade de todos. ${ }^{16}$

Em outras palavras, o dever jurídico se funda na liberdade do arbítrio das outras pessoas, não importando seu conteúdo e sim suas formas de inter-relações, que deverão ser necessariamente livres. Por isso, Kant define o direito como o "conjunto das condições, por meio das quais o arbítrio de um pode estar de acordo com 0 arbítrio de outro segundo uma lei universal da liberdade". 17 o direito, como uma ordem coativa, torna possível a coexistência do arbítrio e garante a máxima liberdade para todos, condição externa necessária para o homem viver sua autonomia. Assim, será justa a ação que puder conviver com a liberdade de todos, segundo leis universais. Disso decorre 0 imperativo universal do direito ${ }^{18}$ como aplicação do imperativo categórico da moral: "age externamente de tal modo que o livre uso de teu arbítrio possa coexistir com a liberdade de todos segundo uma lei universal". ${ }^{19} \mathrm{O}$ direito, como ordem coativa, é, então, um instrumento necessário do ponto de vista moral, imprescindível segundo a lei universal da razão, capaz de orientar as ações externas para o respeito recíproco do arbítrio, na direção da máxima liberdade igual para todos. ${ }^{20}$

O direito e a ética diferem entre si pela forma de suas legislações, mas pertencem a uma mesma moral em sentido amplo e se fundam no mesmo princípio, que é a liberdade, e em uma mesma lei fundamental, que é o imperativo categórico. Os fins éticos dos homens, segundo Kant, os levam a constituírem uma comunidade política, uma vez que somente nela tais fins poderão ser realizados. Nesse contexto, o direito representa uma possibilidade objetiva de consecução do fim ético do homem, da mesma forma que a moralidade é condição subjetiva para a formação de uma entidade jurídico-política. Para o filósofo idealista, 0 direito inato de igual liberdade de todos os homens funciona como critério pré-jurídico que deverá orientar sempre toda a sistemática do direito natural e do direito positivo. É essa igual liberdade que funciona como pressuposto do direito e torna possível o seu sistema de normas. ${ }^{21}$

\section{A MORALIDADE JURÍDICA DOS DIREITOS HUMANOS: A PROPOSTA TRANSCENDENTAL DE OTFRIED HÖFFE}

Dentre as inúmeras tentativas de valorização jurídica da moralidade dos direitos humanos, parece que a proposta transcendental sustentada por Otfried Höffe é a mais adequada para tratar dos direitos humanos no contexto de uma sociedade cada vez mais pluralista e globalizada. Visivelmente influenciado pelas categorias kantianas, Höffe promove uma aproximação entre o direito e a moral 
operada de modo racional, sem as agonias e os ceticismos epistemológicos específicos do debate jurídico que transformou a questão moral numa zona totalmente estranha ao direito. No lugar do cientificismo exagerado, que se manifesta na divisão clássica dos saberes jurídico e moral, Höffe sugere uma relação de correspondência recíproca, apresentada por ele como necessária e indispensável para se fundamentar uma cultura universal sobre os direitos humanos. Sem confundir o direito com a moral, uma vez que parte de uma separação entre ambas as categorias, o autor aponta para o direito e a moral como elementos constituidores daquilo que ele denominou de moral jurídica. Lembra, inicialmente, que a filosofia moral e jurídica sempre se contentaram em apenas separar a moral em sentido positivo, que retrata a idéia de ética, dos usos e costumes, da moral em sentido crítico, que versa sobre as obrigações supremas não-negociáveis, separando ambas do direito. Por sua vez, a idéia de uma moral do direito, continua Höffe, deve ser entendida como uma variação que se desenvolve dentro da moral crítica, de modo que a moral jurídica corresponde àquela parte da moral crítica "cujo reconhecimento se devem as pessoas reciprocamente". ${ }^{22}$

Para o autor alemão, os direitos humanos têm um caráter pré e supra-estatal, pois dizem respeito à pessoa como tal, às exigências e às renúncias mútuas que o homem precisa reconhecer para poder livremente exercer sua humanidade. Antes de serem positivados, os direitos humanos assumem uma posição moral que procede do "dever de reconhecimento que as pessoas se devem umas às outras", um dever que todos os indivíduos assumem, indistintamente, de respeitarem um conjunto de obrigações recíprocas que geram uma vantagem para todos, uma vez que se referem a vantagens irrenunciáveis que possuem relevância transcendental em relação ao ser humano. ${ }^{24}$

Os indivíduos garantem a reciprocidade dos direitos humanos como uma forma de reconhecimento transcendental de tais direitos, que todos se devem mutuamente como condição de possibilidade da própria existência humana enquanto tal. Os direitos humanos, nesse caso, decorrem de deveres humanos recíprocos que obrigam aos sujeitos naturais a reconhecerem e a respeitarem mutuamente tais direitos, notadamente em função de sua condição humana, sem afastar, contudo, a possibilidade/necessidade de, secundariamente, o Estado cumprir a função de protegê-los. ${ }^{25} \mathrm{Na}$ sociedade de co-autores de uma comunidade jurídica, os direitos humanos estabelecem a unidade comum da sociedade préestatal ou mesmo pré-política que, ao fundar-se como Estado, deve promover a institucionalização de tais direitos. Uma vez que não há um direito sem o dever de respeitá-lo e como não há dever sem a possibilidade de coerção, os direitos humanos conferem a cada ser humano o direito moral de se defender contra a lesividade de ações que ataquem as suas liberdades fundamentais, funcionando como mandatos universais para o exercício da coerção, o que, no entanto, não deve ser entendido como portas abertas para a utilização de qualquer tipo de violência. Portanto, "o dever somente se legitima a partir da reciprocidade presente na comutação transcendental, caracterizada, por essa razão, como reciprocidade universal". ${ }^{26}$

Os direitos humanos, nesse cenário, não são outorgados pelo Estado. A necessidade de se universalizar o máximo de liberdade para todos e de se estabelecer exigências comuns, faz de cada indivíduo um sujeito responsável pelo 
reconhecimento de tais direitos. Ou seja, por serem vantajosas para todos os indivíduos, as renúncias recíprocas de liberdades conduzem aos direitos humanos como condição mais favorável para a existência humana, uma vez que existe a real "possibilidade de os indivíduos serem tanto vítimas quanto perpetradores de violência". ${ }^{27}$ Da mesma forma, se reconhece que é melhor para todos que a responsabilidade pelos direitos humanos não seja uma atribuição individual, mas que tal tarefa seja assumida pelo poder público, que deverá reconhecer a suprapositividade dos direitos humanos e seu imperativo jurídico universal. Assim, quando o Estado assume o papel de resolver os conflitos entre os indivíduos, é seu dever organizar a sua ação coercitiva no intuito de proteger os direitos humanos, cuja missão é a própria razão de ser do Estado e a justificativa de sua finalidade mais importante.

É a igual liberdade que "obriga cada membro da comunidade jurídica a reconhecer as condições universais de coexistência da liberdade", ao mesmo tempo em que "impõe a cada indivíduo o dever de garantir esse reconhecimento. Aos membros da comunidade jurídica cumpre conceder as condições, ao Estado o dever de assegurá-las". ${ }^{28} \mathrm{Na}$ qualidade de direitos morais, os direitos humanos não dependem, no que se refere ao seu reconhecimento, de qualquer fator social, cultural ou político, eis que são direitos que os participantes de uma comunidade jurídica devem-se reciprocamente e que o Estado, subsidiariamente, deve a todas as pessoas indistintamente. Enquanto exigências internas da moral, os direitos humanos são pretensões suprapositivas que, ao serem reconhecidas legalmente, passam a integrar 0 rol dos direitos fundamentais, etapa esta de publicização institucional de que nenhuma coletividade nacional ou internacional pode prescindir.

O substantivo moral na categoria "moral jurídica", no entendimento de Höffe, não representa uma característica direcionada ao direito positivo e às suas formas tradicionais de sanção. Não se deve esperar da moral jurídica, ao menos de seu atributo moral, um tipo de punição dura por parte do direito, mas apenas uma sanção branda, uma reação de protesto e uma indignação contra um conjunto de situações que precisam ser modificadas e que, por isso, autorizam essa exigência de mudança. Por outro lado, lembra Höffe, o designativo "jurídica" da expressão "moral jurídica" deve ser compreendido tanto no sentido objetivo como no sentido subjetivo. Isso significa que a moral jurídica é uma moral que pode ser exigida legalmente, que potencializa não apenas uma expectativa, um desejo, mas sobretudo um direito subjetivo de se exigi-la. Justamente por isso a moral jurídica não se reduz às modalidades brandas de punição, às modalidades de sanção exclusivamente morais, pois, no momento em que a moral jurídica integra-se ao direito positivo, passa a aceitar, também, as sanções tipicamente jurídicas. ${ }^{29}$ Neste sentido, a "moral jurídica submete todo o ordenamento jurídico positivo a uma pretensão moral, a qual, na medida em que é admitida, o caracteriza como legítimo ou justo e, no caso de ser rechaçado ou inclusive 'desobedecido', de injusto". 30

Essa exigência da moral jurídica, porém, apresenta-se, de acordo com o autor, elaborada em três níveis. $O$ primeiro destaca que a relação entre os indivíduos e, de um modo geral, a vida em sociedade, por necessidade racional, deve ser conformada pelo direito, isto é, que o direito, a partir de normas comuns, deve imperar sobre a vontade e as opiniões particulares, pois isso, de um modo geral, é a melhor opção para todos. Trata-se, nesse nível, de reconhecer a moral 
como instituidora e legitimadora da forma jurídica de convivência. Höffe descreve essa necessidade moral de a vida social ser organizada de acordo com o direito por meio do seguinte princípio de justiça constitutivo de direito, princípio que consiste, para o autor, em um imperativo jurídico universal: "enquanto essência de regras com validade rigorosamente universal, o direito opõe-se à arbitrariedade pessoal e à violência pessoal, devendo, exatamente, por esse motivo, dominar em todos os lugares entre os homens". ${ }^{31}$ Não se pode esquecer, porém, que se impõe, como condição necessária para o direito, que os indivíduos se reconheçam a si mesmos como sujeitos de direitos e reconheçam todos os demais indivíduos com igual capacidade jurídica, necessária à imputabilidade. Höffe traduz essa exigência na forma de um princípio da protojustiça, nos seguintes termos: "Através de um autoreconhecimento original e um reconhecimento alheio original, todos os membros da mesma espécie de seres imputáveis deverão reconhecer a si próprios e a seus iguais como membros de direito". ${ }^{32}$

Em um segundo nível, a moral jurídica determina que a forma jurídica deve ser respeitada de modo inarredável e que todas as pessoas devem ser tratadas de acordo com as normas, ou seja, ser tratadas com igualdade. Essa exigência da moral jurídica se sustenta na obrigatoriedade de todos serem tratados com igualdade pela legislação. Esses dois primeiros níveis, lembra Höffe, são aceitos sem discussão em praticamente todas as culturas contemporâneas e formam aquilo que o autor chama de uma "herança comum de justiça da humanidade". ${ }^{33}$

Ao contrário dos dois primeiros, o terceiro nível da moral jurídica, constituída pela democracia e pelos direitos humanos, ainda não encontrou solo fértil em todas as nações contemporâneas. Enquanto os dois primeiros níveis garantem um mínimo de moral jurídica e definem a estrutura constituidora do direito, o terceiro apresenta uma riqueza substancial, uma ampliação das pretensões a serem protegidas pelo poder coativo. Esse terceiro nível refere-se diretamente ao conteúdo da moralidade e, também, ao conteúdo normativo do direito, pois diz respeito a um conjunto de escolhas e de valores individuais e sociais que deverão ser garantidos materialmente e introduzidos nas formalidades e nos procedimentos que são objeto dos dois primeiros níveis comentados.

É preciso observar, prossegue Höffe, que o incremento total dos elementos desse terceiro nível não necessariamente ocorre de modo simultâneo em todo o planeta, pois está diretamente relacionado com as políticas públicas e com a realidade cultural e econômica de cada Estado. Desse modo, o autor apresenta três níveis parciais do terceiro nível da moral jurídica: "os direitos humanos como direitos de liberdade, a democracia como os direitos de co-gestão por ela definidos, e uma porcentagem de direitos humanos de caráter político e social". ${ }^{34}$ Do mesmo modo como os níveis da moral jurídica (forma jurídica de convivência; antecedência da igualdade perante a lei; direitos humanos e democracia) estão diferentemente realizados nos diversos países, assim também os três níveis parciais do terceiro nível da moral jurídica são atendidos em diferentes medidas, uma vez que dependem, como se disse, da atuação estatal e do grau de satisfação de cada comunidade. ${ }^{35}$

Os direitos humanos como direitos negativos de liberdade (vida, integridade física, liberdade de expressão e crença religiosa), na condição de conteúdos morais 
normativos do direito, são apresentados pelo autor como decorrentes de uma necessidade universal de se reconhecer a reciprocidade de renúncias à liberdade, como forma de evitar que se coloque em perigo a vida e a ação livre de todos e de cada um em particular, face a possibilidade de todos os indivíduos serem tanto vítimas quanto potenciais sujeitos praticantes de atos de violência. Tais direitos, ainda segundo Höffe, derivam de interesses transcendentais que visam atender ao máximo de liberdade igual para a ação e para a vida de todos, conteúdo normativo que pode ser sintetizado no seguinte princípio de justiça (princípio da maior liberdade igual negativa): 'Que por meio de renúncias recíprocas à liberdade, cada membro do direito obtenha aquela medida máxima de liberdade de ação, a qual, de acordo com o princípio primeiro de justiça, é possível em regras universalmente válidas". ${ }^{36}$

No que tange aos direitos positivos de liberdade, os direitos sociais, a simples renúncia recíproca à violência não será suficiente para garanti-los. Tanto a vida humana em sua dimensão material quanto o desenvolvimento da capacidade de pensar e de falar, dependem de ações positivas para se realizarem. Mas nem todas as sociedades carecem das mesmas necessidades. Por isso, os direitos sociais podem, nesse tocante, configurarem-se dependentes de vários aspectos, como a idade dos sujeitos, da região onde se habita, da realidade econômica, do nível de tecnologia, da cultura, do nível de recursos, etc. Inobstante essa dependência, parece que os direitos sociais encontram sua justificativa - justificativa que é sempre ausente -, segundo Höffe, em sua importância para a capacidade de ação, razão pela qual tais direitos se conectam, em certa medida, aos direitos negativos de liberdade.

Por outro lado, prossegue Höffe, diferentemente desses direitos, a fundamentação dos direitos sociais não é nada simples. São direitos que dificilmente possuem uma tipificação positiva subjetiva clara, uma vez que sua reivindicação está diretamente relacionada à existência de recursos, o que torna praticamente impossível reclamar os direitos humanos desse tipo numa dada situação de escassez. Assim como são dependentes dos recursos, também o são em relação à cultura, ao tipo de vida levado por um dado povo e aos seus conceitos de boa vida em todos os sentidos. Por isso, cada Estado poderá, a seu juízo, definir maneiras diferentes de implementar os direitos sociais, jamais de negá-los. A dependência dos direitos sociais das condições materiais e culturais pode tornar a sua efetivação na realidade social um tanto quanto complexa e, no campo político, altamente controversa.

Outra dificuldade apontada pelo autor alemão é que os direitos sociais não geram, em tese, obrigações a serem cumpridas por todos os indivíduos particularmente. Aduzindo que não estão claras as bases de fundamentação dos direitos sociais, entende que um princípio de justiça distributiva assume uma tarefa fundamental na organização da vida social, mormente para realizar uma distribuição dos recursos cada vez mais escassos no planeta. A necessidade de se distribuir com justiça os recursos necessários à vida obriga a todos os indivíduos reconhecerem um grau de reciprocidade no campo social, muitas vezes indispensável para o próprio exercício dos direitos negativos de liberdade. ${ }^{37}$ 
A partir da efetiva proteção dos diferentes níveis da moral jurídica, é possível, segundo o autor, perceber o grau de moralidade legitimadora de uma determinada ordem social. Assim, continua Höffe, apenas aquele Estado que reconhece as formas jurídicas de convivência, que sustenta a igualdade perante a lei e que defende os direitos de liberdade, a democracia e o Estado social, condição necessária para a afirmação dos direitos humanos, poderá ser considerado como uma organização plenamente legítima do ponto vista moral.

É de se notar ainda que a moral jurídica, como quer Höffe, não é prisioneira de relativismos culturais e de orientações tradicionais. Trata-se de uma moral que deposita sua capacidade crítica unicamente na razão universal e nas experiências de toda a humanidade. 'Uma filosofia moral que se atenha somente a estes dois fatores, à combinação da razão universal com a experiência igualmente universal, sustentada por la conditio humana, pode reclamar com toda a razão a categoria de universal". ${ }^{38}$ A moralidade jurídica não é uma categoria condicionada e dependente de variações histórico-culturais, sujeita a âmbitos de validade particulares ou mesmo resultados de movimentos políticos e econômicos atrelados a determinados países ou culturas dominantes.

Representa, antes, um imperativo universal, o reconhecimento de reciprocidades indispensáveis para se garantir a livre manifestação do gênero humano. Significa o reconhecimento de mutualidades que obrigam o ser humano perante 0 outro, que potencializam e viabilizam 0 homem em sua própria humanidade, ou seja, que garantem ao homem o direito de conduzir sua ação sem prejudicar a ação de qualquer outro. Trata-se de um imperativo universal que deposita na simples condição de ser humano a definição das necessidades e, portanto, dos direitos que são indispensáveis para a manifestação livre da natureza humana. Basta notar que muitos dos direitos que foram universalizados com a modernidade já eram reconhecidos há muito tempo em culturas distintas. Não foi a modernidade, segundo Höffe, que inventou os direitos humanos, sendo apenas o momento histórico que promoveu o seu reconhecimento geral, isto é, o momento em que os indivíduos foram, pela primeira vez, reconhecidos pelo Estado como iguais perante à lei. Pode-se notar, por exemplo, que a proteção do corpo e da vida, o reconhecimento da língua e da razão como propriedades universais e a aceitação de que 0 homem é um animal social são premissas aceitas e válidas indiferentemente em diferentes culturas desde há muito tempo. ${ }^{39}$

No entendimento de Höffe, diante da existência de direitos humanos universais e da necessidade global de sua atuação, não se pode admitir a existência de direitos humanos de caráter nacionalista. ${ }^{40}$ É necessária uma legitimação dos direitos humanos capaz de ser globalizada, capaz de obrigar mutuamente e de modo universal a todas as culturas em diferentes épocas e locais específicos. Somente a mutualidade de cunho universal e abrangente pode sustentar uma cultura de direitos universais "que caracteriza o ser humano tão-somente por ser um ser humano". ${ }^{11}$ Os direitos humanos são indispensáveis para se garantir as condições universais de coexistência da liberdade, razão pela qual não podem ficar reféns dos relativismos e particularismos, nem sempre democráticos e humanistas. A sociedade global não pode operar com uma multiplicidade de fundamentos para os direitos humanos, sob pena de proliferar e sustentar autoritarismos locais em nome de quaisquer concepções de direito à diferença. 
Os direitos humanos fazem parte de uma moral jurídica que permite a cobrança mútua por todos os membros da coletividade, seja em relação a um indivíduo, seja em relação ao próprio Estado, ou até mesmo em relação a outro Estado. Nesse sentido,

os direitos humanos não se fundamentam apenas em ações voluntárias de
um favor social ou político. Trata-se de direitos que os membros da
comunidade jurídica devem uns aos outros e que, subsidiariamente, a
ordem jurídica e estatal deve a todas as pessoas. Nenhuma coletividade e
também nenhuma ordem juŕdica internacional pode abrir mão da
positivação na forma de direitos fundamentais ou também na forma de
objetivos fundamentais do Estado. Por isso, elas possuem dois modos de
existência complementares, mas fundamentalmente distintos quanto ao
método. No interior da moral devida, da justiça, elas são apenas direitos
humanos: pretensões suprapositivas, que, no entanto, uma vez
reconhecidas como direitos positivos, se tornam direitos humanos
enquanto direitos fundamentais de uma coletividade fundada em direito
positivo.

Nota-se, pois, que Höffe diferencia os direitos humanos dos direitos fundamentais. Enquanto que os primeiros fazem parte da "moralidade jurídica universal que resguarda o corpo, a vida, as condições materiais de vida, a língua e a razão e as propriedades humanas universais, a capacidade política específica zôon politikon -, a capacidade jurídica e a capacidade comunitária", ${ }^{43}$ os direitos fundamentais, por sua vez, consubstanciam-se num rol de direitos que o cidadão possui em razão de seu vínculo com o Estado, direitos esses que estão dispostos nos textos constitucionais de cada país.

Esses direitos, lembra Vicente de Paulo Barretto, "poderão ou não consagrar direitos humanos, pois sempre expressam a vontade do legislador em determinado momento histórico". ${ }^{44}$ Os direitos humanos são, a um só tempo, direitos jurídicos porque reconhecidos pela legislação, e direitos morais em decorrência de sua metapositividade, de sua natureza moral que obriga mutuamente as pessoas umas às outras. Por isso, insiste Barretto, não se pode reduzir os direitos humanos aos direitos fundamentais, sob pena de se negar o seu estatuto jurídico-moral e de se esvaziar sua potencialidade crítica, característica que foi fundamental no contraponto aos absolutismos, autoritarismos e totalitarismos que a humanidade produziu nos últimos séculos.

A moral jurídica, portanto, compõe aquilo que pode ser universalizado, que é fundamental pela afirmação do homem como tal, o que de modo algum nega as diferenças no campo do não-universal. Enfim, numa sociedade complexa os direitos humanos, como elementos de uma moralidade jurídica, sugerem o limite do que pode ser universal e o limite do que pode ser relativo; isto é, não são todas as expectativas e demandas que podem ser legitimamente universalizadas, do mesmo modo que nem tudo o que possui apelo relativista pode ser considerado legítimo do ponto dos direitos humanos. Nisso reside o problema da fundamentação ética da igualdade e da diferença numa sociedade que cada vez mais precisa estabelecer padrões mínimos de convivência sem, no entanto, negar as diferenças que constituem a identidade de cada povo. 
Além da razão ética, existem razões político-normativas para se defender a universalidade que a moralidade dos direitos humanos engendra. É moralmente desejável adotar a universalidade dos direitos humanos se as sociedades contemporâneas pretenderem organizar sua convivência recíproca de acordo com o direito e não a partir da violência. É verdade que o paradigma do direito já opera internamente em todas as nações, as quais reconhecem também, em suas versões democráticas, um tratamento jurídico igualitário para todos os seus cidadãos. De fato, um passo a mais precisa ser dado na direção de substancializar o direito pela mutualidade das obrigações que ecoam da moralidade dos direitos humanos, promovendo um direito que limite externa e internamente a soberania estatal, 0 absolutismo das culturas, religiões, tradições, etc., e sirva de paradigma normativo para a coexistência entre as muitas nações, comunidades, religiões, culturas, etc. Os direitos humanos, na condição de direitos morais do homem em decorrência de sua humanidade e não como repositórios de positividade legalista ou de verdades relativas, podem fixar os limites do pluralismo de qualquer tipo e servir de base normativa para que a sociedade contemporânea consiga encontrar respostas e construir as alternativas para os problemas que afetam a humanidade como um todo. $^{45}$

Existem razões comuns bem objetivas para que a humanidade aceite a legitimidade de uma proposta global de direitos humanos. Os desafios da sociedade contemporânea indicam que somente a conjugação dos esforços e a realização de um trabalho comum poderão responder aos grandes problemas que afetam indistintamente todas as nações e pessoas. $O$ crime internacional, o terrorismo, os danos ambientais, a fome, as guerras, a internacionalização dos mercados, entre outros problemas globais, sugerem que o diálogo a partir dos direitos humanos seja algo necessário e desejável, sobretudo para se evitar soluções imperialistas que, propostas na onda neoliberal ou pela contingência de um direito internacional clássico, consagrem e aumentem privilégios estatais e coorporativos, fulminando com a possibilidade de se construir uma ação baseada na responsabilidade e na reciprocidade de obrigações comuns. ${ }^{46}$

É importante que o paradigma jurídico seja aceito como uma realidade mundial no âmbito interno de cada Estado, como também é fundamental que os cidadãos de um Estado sejam tratados de forma igual pelo direito. É imprescindível, para além disso, que se avance na direção de se reconhecer institucionalmente os direitos humanos - uma forma de substancialização do direito e da democracia como exigências recíprocas devidas entre Estados e indivíduos, capazes de alimentar uma universalidade jurídica inegociável e orientadora da coexistência humana em todas as esferas de convivência, seja na nação, na cultura, na religião, na etnia, na raça, no gênero, etc. Sujeitos que estão os homens e os Estados a sofrerem agressões e de também as praticarem, apenas a normatização das renúncias recíprocas à violência, das responsabilidades comuns e dos deveres mútuos, promoverá novas expectativas práticas para os direitos humanos enquanto exigências morais devidas ao homem em função de sua humanidade, sobretudo no momento em que as formas materiais de sua existência revelam-se especialmente complexas. $^{47}$ 


\section{CONCLUSÕES}

A moralidade jurídica dos direitos humanos, para além de abrir uma perspectiva para a ação jurídico-política cosmopolita, vincula duplamente os indivíduos e os Estados, isoladamente e entre si: em primeiro lugar, a moral crítica obriga, como um dever em si mesmo, a preservar as condições de vida no máximo grau de igualdade estendida a todas as pessoas ao mesmo tempo, ou seja, reconhecendo os direitos humanos como reciprocidades inegociáveis capazes de obrigar a ação estatal e individual nos termos de uma máxima universal; em segundo lugar, a moralidade orienta o direito positivo no sentido de reconhecer institucionalmente os direitos humanos como critérios objetivos e como condição de possibilidade para a afirmação ética da humanidade presente no homem. ${ }^{48} \mathrm{Enfim}$, a moralidade jurídica dos direitos humanos estabelece possibilidades para se avaliar a legitimidade das instituições, permite encontrar alternativas para a sociedade contemporânea sustentadas em regras comuns de convivência e respeito aos direitos e, sobretudo, exige do homem o reconhecimento de uma humanidade que Ihe é inerente e independente de relativismos e particularidades de qualquer ordem.

Reconhecer a humanidade do homem como tal como o fundamento da universalidade dos direitos humanos é uma forma de superar os traços particularistas que aprisionam os direitos humanos ao contexto de tradições excludentes e de considerar sua exigência moral e jurídica que obriga mutuamente os homens entre si a respeitarem a dignidade presente em cada um. A coexistência moral de todos os homens, independentemente do pertencimento a determinada condição histórico-cultural, deve orientar de forma direta a compreensão também moral dos direitos humanos. Direitos esses que, sob este viés, teriam por escopo, antes de tudo, levar o homem à reflexão sobre a sua condição última enquanto ser universal, fortalecendo a compreensão acerca de sua existência singular e elevando o tratamento jurídico de suas relações a um mínimo ético.

\section{JURIDICAL MORALITY OF HUMAN RIGHTS AS THE CONDITION FOR THEIR UNIVERSALITY}

\section{ABSTRACT}

This text aims to sustain the presence of a juridical morality present in the human rights as a condition of their universality. Starting the journey by the concept of moral rights, and after visiting the approach of rights and morality in the Kantian reading, it comes to the analysis of the juridical morality of human rights, which is understood as a moral and juridical obligation of recognition that people must have about each other, as obligation that all individuals assume, without distinction, to respect a set of reciprocal obligations that generate an advantage for all, since they are based on the humanity of man as such.

Keywords: Human rights. Juridical morality. Kant. Otffried Höffe. 


\section{NOTAS}

1 Doutor em Direito pela Unisinos e Mestre em Direito pela UFSC. Professor do Curso de Graduação em Direito e do Mestrado em Desenvolvimento na Universidade Regional do Noroeste do Estado do Rio Grande do Sul (UNIJUí) e no Instituto Cenecista de Ensino Superior de Santo Ângelo (IESA). Advogado.

2 LAPORTA, Francisco. Sobre el concepto del derechos humanos. In: Doxa. Cuadernos de Filosofia del Derecho. Alicante: Universidad de Alicante; Biblioteca Digital Miguel Cervantes, n. 4, 1987. No mesmo sentido, AÑóN, José García. Los derechos humanos como derechos morales: aproximación a unas teorias com problemas de concepto, fundamento y validez. In: BALLESTROS, Jesús (Editor). Derechos humanos. Madrid: Tecnos, 1992.

3 LAPORTA, Francisco. Sobre el concepto del derechos humanos. In: Doxa. Cuadernos de Filosofia del Derecho. Alicante: Universidad de Alicante; Biblioteca Digital Miguel Cervantes, n. 4, 1987.

4 LAPORTA, Francisco. Sobre el concepto del derechos humanos, p. 27-28.

5 Para uma crítica aos direitos humanos como direitos morais, sugere-se a leitura de DE LUCAS, Javier. Algunos equívocos sobre el concepto y fundamentación de los derechos humanos. In: BALLESTROS, Jesús (Editor). Derechos humanos. Madrid: Tecnos, 1992. Os mesmos argumentos podem ser encontrados em outro texto do mesmo autor: DE LUCAS, Javier. Uma nota sobre el concepto y la fundamentación de los derechos humanos. (A propósito de la polémica sobre los derechos morales) In: Doxa. Cuadernos de Filosofia del Derecho. Alicante: Universidad de Alicante; Biblioteca Digital Miguel Cervantes, n. 10, 1991.

6 LAPORTA, Francisco. Sobre el concepto del derechos humanos. In: Doxa. Cuadernos de Filosofia del Derecho. Alicante: Universidad de Alicante; Biblioteca Digital Miguel Cervantes, n. 4, 1987.

7 DWORKIN, Ronald. Levando os direitos a sério. São Paulo: Martins Fontes, 2002.

8 BULYGIN, Eugenio. Sobre el status ontológico de los derechos humanos. In: Doxa. Cuadernos de Filosofia del Derecho. Alicante: Universidad de Alicante; Biblioteca Digital Miguel Cervantes, n. 4, 1997, p. 82.

9 NINO, Carlos Santiago. Ética y derechos humanos. Un ensayo de fundamentación. 2. ed. Buenos Aires: Editorial Astrea, 1989. Consultar também SPECTOR, Horácio. La filosofía de los derechos humanos. In: Isonomía. n. 15, octubre de 2001 e BULYGIN, Eugenio. Sobre el status ontológico de los derechos humanos. In: Doxa. Cuadernos de Filosofia del Derecho. Alicante: Universidad de Alicante; Biblioteca Digital Miguel Cervantes, n. 4, 1997.

10 KANT, Immanuel. Fundamentação da metafísica dos costumes e outros escritos. Tradução de Leopoldo Holzbach. São Paulo: Martin Claret, 2004 , p. 52. Nas três versões do imperativo categórico, é possível verificar a presença da idéia de homem racional como um fim em si mesmo, a defesa da universalidade dos juízos morais e a possibilidade de se determinar as máximas universais valendo-se de fórmulas.

11 KANT, Immanuel. Fundamentação da metafísica dos costumes e outros escritos, p. 59.

12 HERNÁNDEZ. José López. La fundamentación del derecho en Kant. In: Anuário de Filosofia del Derecho. Madrid: Nueva Época, n. IX, 1992, p. 395-406.

13 Mesmo Bobbio parece não ter identificado na leitura kantiana a existência de imperativos categóricos no direito, de modo que também considera impossível a definição de um conceito moral de direito. BOBBIO, Norberto. Direito e Estado no pensamento de Emanuel Kant. Tradução de Alfredo Fait. Brasília: UnB, 1984.

14 Cf. HÖFFE, Otfried. Principes du droit. Ethique, théorie juridique et philosophie sociale. Paris: Cerf, 1993. Cap. v, p. 91-107; HÖFFE, Otfried. O imperativo categórico do direito: uma interpretação da 'introdução à doutrina do direito". In: Studia Kantiana - Revista da Sociedade Kant Brasileira. v. 1, n. 1.

15 вОВBIO, Norberto. Direito e Estado no pensamento de Emanuel Kant Tradução de Alfredo Fait. Brasília: UnB, 1984, p. 59. Na mesma direção, Salgado destaca que 'toda a questão da diferença entre direito e moral está na distinção entre liberdade considerada no seu interno e liberdade no seu momento externo, sem perder de vista que se trata da mesma liberdade, comum tanto ao direito como à moral". Cf. SALGADO, Joaquim Carlos. $A$ idéia de justiça em Kant. Seu fundamento na liberdade e na igualdade. Belo Horizonte: UFMG, 1986, p. 267.

16 PÉREZ-LUÑo, Antonio-Enrique; PELÁEZ, Francisco José Contreras. Kant e los derechos humanos. In: PECES-BARBA MARTínEZ, Gregório; FERNÁNDEZ GARCIA, Eusébio; ROIG, Rafael de Asís (Orgs.). Historia de los derechos fundamentales. v. II. Madrid: Dykinson, 2001, p. 451-568.

17 KANT, Emanuel. Doutrina do direito. Tradução de Edson Bini. São Paulo: Ícone, 1993, p. 49.

18 Assim, lembra Höffe, 'Kant introduit une troisiéme variante pour la morale juridique, la loi juridique universelle (et à nouveau morale). Puisque ce que traitent déjà le concept du droit et le principe juridique y est formulé comme un impératif, nous avons enfin trouvé l'impératif catégorique juridique exact: 'Agis extérieurement de telle sorte que le libre usage de ton arbitre puisse coexister avec la liberté de chacun suivant une loi universelle' (III, 479). Mais, puisque cette compatibilité des libertés d'action selon une loi universelle est déjà abordée dans le concept et dans le principe du droit, elles peuvent aussi valoir comme formulations de l'impératif catégorique juridique". HÖFFE, Otfried. Principes du droit. Ethique, théorie juridique et philosophie sociale. Paris: Cerf, 1993. Cap. v, p. 100.

19 KANT, Emanuel. Doutrina do direito, p. 50 
20 HÖFFE, Otfried. Immanuel Kant. Barcelona: Herder, 1986. Ver também SALGADO, Joaquim Carlos. A idéia de justiça em Kant. Seu fundamento na liberdade e na igualdade. Belo Horizonte: UFMG, 1986.

21 PELÁEZ, Francisco José Contreras. La idea de igualdad en el pensamiento político de Kant. In: Derechos y libertades. Revista del Instituto Bartolomé de Las Casas. Madrid: Universidad Carlos III, n. 9, julio/deciembre de 2000.

22 HÖFFE, Otfried. Derecho intercultural. Traducción de Rafael Sevilla. Barcelona: Gedisa, 2000, p. 51.

23 MOREIRA, Luiz. Direitos Humanos: a proposta transcendental de Otfried Höffe. In: Síntese - Revista de Filosofia. v. 29 , n. 93 , 2002.

24 HÖFFE, Otfried. Estudios sobre teoría del derecho y la justicia. México: Fontamara, 1997, p. 65-84.

25 HÖFFE, Otfried. Justiça política. Tradução de Ernildo Stein. São Paulo: Martins Fontes, 2001.

26 HÖFFE, Otfried. A democracia no mundo de hoje. Tradução de Tito Lívio Cruz Romão. São Paulo: Martins Fontes, 2005 , p. 64.

27 HÖFFE, Otfried. A democracia no mundo de hoje, p. 73.

28 HÖFFE, Otfried. O que é justiça. Tradução de Peter Naumann. Porto Alegre: EdiPucrs, 2003, p. 83.

29 HÖFFE, Otfried. Derecho intercultural. Traducción de Rafael Sevilla. Barcelona: Gedisa, 2000.

30 HÖFFE, Otfried. Derecho intercultural. Traducción de Rafael Sevilla. Barcelona: Gedisa, 2000, p. 54.

31 HÖFFE, Otfried. A democracia no mundo de hoje. Tradução de Tito Lívio Cruz Romão. São Paulo: Martins Fontes, 2005 , p. 63.

32 HÖFFE, Otfried. A democracia no mundo de hoje, p. 95.

33 HÖFFE , Otfried. Derecho intercultural. Derecho intercultural. Traducción de Rafael Sevilla. Barcelona: Gedisa, 2000 , p. 55.

34 HÖFFE, Otfried. Derecho intercultural, p. 55.

35 A esse respeito, consultar BARRETTO, Vicente de Paulo. O direito no século XXI: desafios epistemológicos. In: Crítica à dogmática. Dos bancos acadêmicos à prática dos tribunais. Revista do Instituto de Hermenêutica Jurídica. n. 3. Porto Alegre: Instituto de Hermenêutica, 2005.

36 HÖFFE, Otfried. A democracia no mundo de hoje. Tradução de Tito Lívio Cruz Romão. São Paulo: Martins Fontes, 2005 , p. 76.

37 A abordagem liberal de Höffe parece ser pouco satisfatória quando enfrenta os direitos sociais. Não se pode separar de modo rigoroso, como faz o autor, os direitos sociais dos direitos individuais utilizando-se de uma escala de importância. Muitas vezes os direitos sociais, e isso o autor reconhece, apresentam-se como indispensáveis para o exercício de um direito individual, o que elide a possibilidade de se escalonar a preponderância de um direito sobre o outro. Também não se pode concordar com Höffe quando aduz que os direitos sociais não geram, em tese, obrigações individuais. Ora, os Estados são legitimados para agirem de forma interventiva no sentido de viabilizarem a prestação de tais direitos mesmo contra a vontade dos indivíduos isoladamente considerados. Isso não conduz, por certo, uma obrigação direta para o indivíduo, mas obriga a coletividade como um todo na consecução de um determinado fim, que, no caso dos direitos sociais, está diretamente relacionado à prestação das condições materiais mínimas para uma existência humana digna.

38 HÖFFE, Otfried. Derecho intercultural. Traducción de Rafael Sevilla. Barcelona: Gedisa, 2000, p. 56.

39 HÖFFE, Otfried. Derecho intercultural. Traducción de Rafael Sevilla. Barcelona: Gedisa, 2000

40 HÖFFE, Otfried. Estados nacionais e direitos humanos na era da globalização. In: MERLE, Jean-Christophe; MOREIRA, Luiz (Orgs.). Direito e legitimidade. São Paulo: Landy, 2003.

41 HÖFFE, Otfried. Estados nacionais e direitos humanos na era da globalização, p. 315.

42 HÖFFE, Otfried. $O$ que é justiça. Tradução de Peter Naumann. Porto Alegre: EdiPucrs, 2003. p. 83. No mesmo sentido, HÖFFE, Otfried. Derecho intercultural. Traducción de Rafael Sevilla. Barcelona: Gedisa, 2000, p. 168: "Os direitos humanos são portanto direitos jurídicos e, também, suprapositivos, morais".

43 BARRETTO, Vicente de Paulo. O direito no século XXI: desafios epistemológicos. In: Crítica à dogmática. Dos bancos acadêmicos à prática dos tribunais. Revista do Instituto de Hermenêutica Jurídica. n. 3. Porto Alegre: Instituto de Hermenêutica, 2005, p. 300. Na mesma direção, PÉREZ-LUÑo, Antonio-Enrique. Los derechos fundamentales. Madrid: Tecnos, 1995, p. 29 e seg. Refere Pérez-Luño que o caráter de universalidade dos direitos humanos, diferentemente dos direitos fundamentais, constitui sua condição deontológica, um dever-ser valorativo que deverá fundamentar a ordem jurídica dos Estados de direito.

44 BARRETTO, Vicente de Paulo. O direito no século XXI: desafios epistemológicos, p. 300.

45 AMUCHASTEGUI, Jesús González. ¿Son los derechos humanos universales? In: Anuario de Filosofia del Derecho. Madrid: Nueva Época, n. XV, 1998, p. 49-110.

46 HEGARTHY, Ângela; LEONARD, Siobhan. Direitos do homem. Uma agenda para o século XXI. Tradução de João C. S. Duarte. Lisboa: Piaget, 1999.

47 HÖFfE, Otfried. A democracia no mundo de hoje. Tradução de Tito Lívio Cruz Romão. São Paulo: Martins Fontes, 2005. 


\section{REFERÊNCIAS}

AMUCHASTEGUI, Jesús González. ¿Son los derechos humanos universales? In: Anuario de Filosofía del Derecho. Madrid: Nueva Época, n. XV, 1998, p. 49-110.

AÑóN, José García. Los derechos humanos como derechos morales: aproximación a unas teorias com problemas de concepto, fundamento y validez. In: BALLESTROS, Jesús (Editor). Derechos humanos. Madrid: Tecnos, 1992.

BARRETTO, Vicente de Paulo. $O$ direito no século XXI: desafios epistemológicos. In: Crítica à dogmática. Dos bancos acadêmicos à prática dos tribunais. Revista do Instituto de Hermenêutica Jurídica. n. 3. Porto Alegre: Instituto de Hermenêutica, 2005.

BIELEFELDT, Heiner. Filosofia dos direitos humanos. Tradução de Dankwart Bernsmüller. São Leopoldo: Unisinos, 2000.

BOBBIO, Norberto. Direito e Estado no pensamento de Emanuel Kant. Tradução de Alfredo Fait. Brasília: UnB, 1984.

BULYGIN, Eugenio. Sobre el status ontológico de los derechos humanos. In: Doxa. Cuadernos de Filosofia del Derecho. Alicante: Universidad de Alicante; Biblioteca Digital Miguel Cervantes, n. 4, 1997.

BULYGIN, Eugenio. Sobre el status ontológico de los derechos humanos. In: Doxa. Cuadernos de Filosofia del Derecho. Alicante: Universidad de Alicante; Biblioteca Digital Miguel Cervantes, n. 4, 1997.

DE LUCAS, Javier. Algunos equívocos sobre el concepto y fundamentación de los derechos humanos. In: BALLESTROS, Jesús (Editor). Derechos humanos. Madrid: Tecnos, 1992.

DE LUCAS, Javier. Una nota sobre el concepto y la fundamentación de los derechos humanos. (A propósito de la polémica sobre los derechos morales) In: Doxa. Cuadernos de Filosofia del Derecho. Alicante: Universidad de Alicante; Biblioteca Digital Miguel Cervantes, n. 10, 1991.

DÍAZ-OTERO, Eduardo; OLIVAS, Enrique. Los viejos conceptos y las nuevas realidades en la integración de los derechos humanos. In: Doxa. Cuadernos de Filosofia del Derecho. Alicante: Universidad de Alicante; Biblioteca Digital Miguel Cervantes, n. 15-16, 1994, p. 675-693.

DWORKIN, Ronald. Levando os direitos a sério. São Paulo: Martins Fontes, 2002.

ENGELHARD, Philippe. L'homme mondial. Paris: Arléa, 1996.

FERNANDÉZ, Eusébio. Teoria de la justicia y derechos humanos. Madrid: Debate, 1984.

HABERMAS, Jürgen. $\boldsymbol{A}$ inclusão do outro. Estudos de teoria política. Tradução de George Sperber e Paulo Astor Soethe. São Paulo: Edições Loyola, 2002.

HEGARTHY, Ângela; LEONARD, Siobhan. Direitos do homem. Uma agenda para o século XXI. Tradução de João C. S. Duarte. Lisboa: Piaget, 1999. 
HERNÁNDEZ. José López. La fundamentación del derecho en Kant. In: Anuário de Filosofia del Derecho. Madrid: Nueva Época, n. IX, 1992.

HÖFFE, Otfried. $A$ democracia no mundo de hoje. Tradução de Tito Lívio Cruz Romão. São Paulo: Martins Fontes, 2005.

HÖFFE, Otfried. Derecho intercultural. Traducción de Rafael Sevilla. Barcelona: Gedisa, 2000.

HÖFFE, Otfried. Estados nacionais e direitos humanos na era da globalização. In: MERLE, Jean-Christophe; MOREIRA, Luiz (Orgs.). Direito e legitimidade. São Paulo: Landy, 2003.

HÖFFE, Otfried. Estudios sobre teoría del derecho y la justicia. México: Fontamara, 1997.

HÖFFE, Otfried. Immanuel Kant. Barcelona: Herder, 1986.

HÖFFE, Otfried. Justiça política. Tradução de Ernildo Stein. São Paulo: Martins Fontes, 2001.

HÖFFE, Otfried. O imperativo categórico do direito: uma interpretação da 'introdução à doutrina do direito". In: Studia Kantiana - Revista da Sociedade Kant Brasileira. v. 1, n. 1.

HÖFFE, Otfried. $O$ que é justiça. Tradução de Peter Naumann. Porto Alegre: EdiPucrs, 2003.

HÖFFE, Otfried. Principes du droit. Ethique, théorie juridique et philosophie sociale. Paris: Cerf, 1993.

KANT, Emanuel. Doutrina do direito. Tradução de Edson Bini. São Paulo: Ícone, 1993.

KANT, Immanuel. Fundamentação da metafísica dos costumes e outros escritos. Tradução de Leopoldo Holzbach. São Paulo: Martin Claret, 2004.

LAPORTA, Francisco. Sobre el concepto del derechos humanos. In: Doxa. Cuadernos de Filosofia del Derecho. Alicante: Universidad de Alicante; Biblioteca Digital Miguel Cervantes, n. 4, 1987.

MARITAIN, Jacques. El hombre y el Estado. Buenos Aires: Club de Lectores, 1984.

MOREIRA, Luiz. Direitos Humanos: a proposta transcendental de Otfried Höffe. In: Síntese - Revista de Filosofia. v. 29, n. 93, 2002.

NINO, Carlos Santiago. Ética y derechos humanos. Un ensayo de fundamentación. 2. ed. Buenos Aires: Editorial Astrea, 1989.

NINO, Carlos Santiago. Sobre os derechos morales. In: Doxa. Cuadernos de Filosofia del Derecho. Alicante: Universidad de Alicante; Biblioteca Digital Miguel Cervantes, n. 7, 1990.

PELÁEZ, Francisco José Contreras. La idea de igualdad en el pensamiento político de Kant. In: Derechos y libertades. Revista del Instituto Bartolomé de Las Casas. Madrid: Universidad Carlos III, n. 9, julio/deciembre de 2000.

PÉREZ-LUÑO, Antonio-Enrique. Derechos humanos, Estado de derecho y constitución. 6. ed. Madrid: Tecnos, 1999. 
PÉREZ-LUÑO, Antonio-Enrique. Los derechos fundamentales. Madrid: Tecnos, 1995.

PÉREZ-LUÑo, Antonio-Enrique; PELÁEZ, Francisco José Contreras. Kant e los derechos humanos. In: PECES-BARBA MARTíNEZ, Gregório; FERNÁNDEZ GARCIA, Eusébio; ROIG, Rafael de Asís (Orgs.). Historia de los derechos fundamentales. v. II. Madrid: Dykinson, 2001, p. 451-568.

SALGADO, Joaquim Carlos. A idéia de justiça em Kant. Seu fundamento na liberdade e na igualdade. Belo Horizonte: UFMG, 1986, p. 267.

SEN, Amartya Kumar. Desenvolvimento como liberdade. Tradução de Laura Teixeira Motta. São Paulo: Companhia das Letras, 2000.

SPECTOR, Horácio. La filosofía de los derechos humanos. In: Isonomía. n. 15, octubre de 2001.

Recebido para publicação 17/03/2009

Aceito para publicação 09/12/2009 